\title{
"NOVA" ELITE NO BRASIL? Sindicalistas \\ e ex-sindicalistas no mercado financeiro
}

\section{Maria Chaves Jardim*}

\begin{abstract}
Resumo: $O$ artigo argumenta sobre a possível formação de uma "nova" elite no Brasil, oriunda do meio sindical e que atualmente está presente no mercado financeiro. Tem como metodologia a realização de entrevistas com sindicalistas, ex-sindicalistas e dirigentes de fundos de pensão, bem como o resgate da história de vida de determinados atores sociais considerados peças-chave na temática dos fundos de pensão. Sugere-se que tem ocorrido uma reconversão de determinados sindicalistas, os quais passam a dialogar com o mercado financeiro na temática de fundos de pensão. Como consequência, evidenciam-se diversas tensões e disputas entre os sindicalistas que se interessam por fundos de pensão (vanguarda financeira) e os sindicalistas que negam a nova estratégia sindical (sindicalistas tradicionais).
\end{abstract}

Palavras-chave: "elite sindical"; sindicalista tradicional; vanguarda financeira; fundos de pensão; mercado financeiro.

\section{Introdução}

$\mathrm{O}$ artigo argumenta a respeito do surgimento de uma "nova" elite no Brasil, a qual é oriunda do mundo sindical e atualmente está presente no mercado financeiro, sobretudo na criação e gestão de fundos de pensão.

A tese é que Ricardo Berzoini e Luis Gushiken são os principais responsáveis pela base moral na construção do mercado de fundos

\footnotetext{
* Doutora em Ciências Sociais (UFSCar). Pesquisadora do Núcleo de Sociologia Econômica e das Finanças (NESEFI). Pós-Doutoranda na Fondation Maison des Sciences de l'Homme (FMSH) onde foi acolhida pelo Centre d'Étude des Mouvements Sociaux (CEMS/Paris). Pesquisadora convidada no Institut de Recherches Économiques et Sociales (IRES/Paris). E-mail: majardim@dep.ufscar.br
} 
de pensão do governo Lula. São considerados pela pesquisa como arquitetos-líderes e divulgadores de opinião, de forma a influenciar a visão de mundo de determinados segmentos sindicais a respeito dos fundos de pensão como nova forma de solidariedade. Para tanto, contaram com o apoio do secretário da Previdência Complementar do governo Lula, Adacir Reis, de sindicalistas e de ex-sindicalistas, junto com os quais se tornaram os "empreendedores morais" (Becker, 1963) do capitalismo de fundo de pensão.

O texto argumenta que, realizando um trabalho cotidiano com o apoio do Governo, de diversas instituições do mercado de fundos de pensão e de sindicalistas da CUT -, determinados atores sociais, que a pesquisa denomina provisoriamente como "elite sindical" (Ricardo Berzoini, Luis Gushiken, Adacir Reis e militantes da CUT), buscam alterar as convenções sociais dos sindicalistas no que se refere à temática dos fundos de pensão.

A mudança de convenção social percebida em certos sindicalistas - que passaram a influenciar e a nominar o mundo social a partir da positivação da idéia dos fundos de pensão -, será denominada nesta pesquisa como "reconversão dos sindicalistas". Na perspectiva do artigo, os fundos de pensão aceleraram o processo de (re)conversão dos sindicalistas e ativaram as práticas de "negação da especulação", em detrimento de um "capitalismo moral". Essas e outras questões serão discutidas no decorrer do artigo.

\section{Formação da elite de fundos de pensão}

As instituições e atores sociais que se dedicam à temática dos fundos de pensão no Brasil têm em comum o interesse pela criação de uma nova "elite dirigente" dos fundos de pensão e defensora da ética moralizante no mercado. Trata-se de um processo criado e iniciado por uma "elite" oriunda do meio sindical, sobretudo do sindicalismo bancário de São Paulo, que trabalha para consolidar a 
idéia dos fundos de pensão. Como formadora de opinião, essa "elite" tem buscado a aliança de diversos e diferentes atores que, até então, jamais haviam dialogado entre si, tais como atores do mercado financeiro, empresários do setor de previdência complementar, membros do governo Lula e sindicalistas.

Num primeiro momento, o papel de tal "elite sindical" é o de desenvolver a crença em torno dos fundos de pensão; num segundo momento, trabalhar para a "reconversão" de sindicatos e sindicalistas. Como reconversão, entendem-se, no sentido de Bourdieu (2001), as mudanças através das quais somos levados a novos gêneros, a novas disciplinas, a novos objetos, vividos como conversões, o que implica, ainda segundo esse autor, uma "mudança de visão de mundo". Finalmente, essa "elite" busca colaborar na formação dos sindicalistas e na difusão dos fundos de pensão enquanto ideário de "moralização" do capitalismo.

Portanto, entender quem constitui essa "elite", implica entender como a "elite sindical" tem poder de criar e, sobretudo, de manter consenso sobre uma "agenda alternativa" de luta, mesmo na condição de outsiders do mercado financeiro. Nesse sentido, a pesquisa buscou compreender a capacidade de tais outsiders em construir e principalmente, em consolidar essa pauta considerada inovadora, polêmica e ambígua. O argumento é que isso só foi possível graças à institucionalização dos fundos de pensão possibilitada pelo governo Lula, que pensa os fundos de pensão como estratégia de inclusão social e de "moralização/domesticação" do capitalismo (Jardim, 2008).

Para entender quem constitui a "elite sindical de fundos de pensão", a pesquisa empírica mapeou a trajetória dos principais "empreendedores morais" (Becker, 1963) dos fundos de pensão. $\mathrm{O}$ artigo focará, especialmente, o caso de Luis Gushiken, Ricardo Berzoini e Adacir Reis. 
Durante o trabalho de campo foi possível observar que, apesar das trajetórias individuais, em certa medida, os membros dessa "elite" são oriundos do setor bancário de São Paulo, e fazem parte do núcleo formulador das políticas do PT; passaram pela FGV/SP, são de origem social de classe média, do sexo masculino, considerados brancos e heterossexuais. Mulheres, pretos ou índios inexistem nesse espaço social, onde, da mesma forma, a regra "da boa etiqueta" não possibilita espaço para as "posturas desviantes", como o homossexualismo.

Além de agentes do setor bancário, citam-se sindicalistas denominados provisoriamente de "classe média", advindos dos setores eletricitários e telefônico, especialmente das regiões de São Paulo, onde o processo está mais ativo. É importante lembrar que, mais recentemente, determinados sindicalistas do setor metalúrgico passaram a se interessar pelo tema.

A pesquisa acredita que os efeitos da formação na FGV-SP e a militância no sindicato dos Bancários de São Paulo tiveram influência sobre todo o universo das representações simbólicas dos atores sociais que passarão a se interessar por fundos de pensão. É no ambiente da FGV-SP e do Sindicato dos Bancários que se conheceram e passaram a compartilhar códigos. Assim sendo, detentores de um conjunto de crenças diferentes daquelas dos sindicalistas que não tiveram tal trajetória de vida, esses, que denominamos provisoriamente como "vanguarda financeira", possuem uma doxa diferenciada daquela que circula no sistema de "representação tradicional" dos sindicatos. Existe, nesse grupo, uma luta pela classificação social, no que se refere à temática dos fundos de pensão.

Ocorre, ainda, uma transformação nas convenções sociais cognitivas, no sentido de Mary Douglas (1998), com uma consequente ruptura entre a visão de mundo dos sindicalistas do passado e dos sindicalistas do presente. 
Pela perspectiva de Bourdieu, o artigo sugere, em certa medida, um conflito de habitus entre a "elite tradicional dos fundos de pensão", que defende o "capitalismo selvagem", o "lucro pelo lucro", e a "vanguarda sindicalista" dos fundos, que é defensora de um conjunto de ferramentas e/ou retóricas como boa governança corporativa, sustentabilidade, investimentos éticos apoiando-se nos fundos de pensão para a construção de novas configurações do capitalismo brasileiro. Assim sendo, trata-se de novos enquadramentos cognitivos dos atores envolvidos, enquadramentos esses que, necessariamente, levam a transformações nos campos econômico, político, sindical e, em certa medida, no campo do poder.

Como observado em trabalho empírico, os sindicalistas que começam a se interessar por fundos de pensão passam a frequentar ambientes empresariais, a realizar leituras relacionadas com o mercado e a convencer (sem querer e sem saber) a si e ao outro dessa nova "convenção social", promovendo, em certa medida, uma naturalização da crença dos fundos de pensão como alternativa à aposentadoria.

É importante esclarecer que os sindicalistas que defendem e administram os fundos de pensão, exercem ainda, seu "tradicional" papel de militantes sindicais. Como exemplo ilustrativo, cite-se o caso da sindicalista entrevistada no Sindicato dos Bancários de Campinas, que faz parte, ao mesmo tempo, do conselho de gestão do Fundo de Pensão dos Funcionários da Caixa Econômica Federal (Funcef) e da direção de tal sindicato.

A autora deste artigo teve a oportunidade de acompanhar a sindicalista em reuniões do Funcef. Naquele momento, a sindicalista incorporou o papel de empresária num espaço dominado pelos homens, tanto na postura física, na gesticulação, nas palavras, nas vestimentas, dentre outros elementos. Em outro momento, durante a greve dos bancários em 2005, encontramos a mesma sindicalista em 
frente à Caixa Econômica Federal, localizada na Avenida Gliceris, em Campinas, gritando palavras de ordem em um microfone, trajando boné, jeans, tênis e camisetas que trazia as frases de efeito: “Agora é a hora" e "Lula, cadê o dinheiro dos bancários?".

\section{Dados do mercado de fundos de pensão}

Os fundos de pensão do Brasil foram criados no governo militar, em 1977, e desde então têm passado por inúmeras transformações. No ano de 2005 acumulavam recursos em volume superior a R $\$ 290$ bilhões, representando $16 \%$ do Produto Interno Bruto (PIB). Das 370 entidades de previdência privada fechada, 82 eram de caráter estatal, 277 de natureza privada e 11 de natureza "instituidor" ou fundo de pensão sindical, conforme mostra a Tabela 1 .

Tabela 1 - Quantidade de entidades de previdência privada por tipo de patrocínio e instituidor, segundo tipo de administração de recursos e número de patrocinadores - dez. 2005

\begin{tabular}{|c|c|c|c|c|c|c|}
\hline \multirow{2}{*}{$\begin{array}{l}\text { Pa trocinio/ } \\
\text { Instituidor }\end{array}$} & \multicolumn{5}{|c|}{ Tipo de Admin istraçă o dos Recursos Financeiros Total } & \multirow{2}{*}{ Patrocinadores } \\
\hline & Externa & Interna & ${ }^{*}$ Mista & *Não Informado & & \\
\hline Público & 6 & 41 & 35 & - & 82 & 258 \\
\hline Privado & 175 & 47 & 45 & 10 & 277 & 1.779 \\
\hline Instituidor & 5 & - & - & 6 & 11 & - \\
\hline Total & 186 & 88 & 80 & 16 & 370 & 2.037 \\
\hline
\end{tabular}

Dentre as 370 entidades de fundos de pensão do país, o Quadro 1 apresenta com maior patrimônio de patrocínio público e de patrocínio privado, respectivamente. 


\section{Quadro 1 - Relação das 10 maiores entidades de previdência complementar por tipo de patrocínio, segundo ativos de investimento - dez. 2004}

\begin{tabular}{|cll|}
\hline \multicolumn{3}{|c|}{ Patrocínio público } \\
\hline Posição & Sigla da entidade & Valor (R\$ mil) \\
\hline $1^{\text {o }}$ & Previ/BB & $70.332 .028,92$ \\
$2^{\text {o }}$ & Petros & $24.986 .337,44$ \\
$3^{\text {o }}$ & Funcef & $17.997 .362,80$ \\
$4^{\text {o }}$ & Centrus & $6.203 .317,31$ \\
$5^{\text {o }}$ & Forluz & $4.205 .726,05$ \\
$6^{\text {o }}$ & Real Grandeza & $3.372 .646,06$ \\
$7^{\circ}$ & Fapes & $3.052 .957,22$ \\
$8^{\text {o }}$ & Fundação Copel & $2.616 .001,21$ \\
$9^{\text {o }}$ & Postalis & $2.249 .000,12$ \\
$10^{\text {o }}$ & Refer & $2.045 .325,21$ \\
\hline Total 10 maiores & $\mathbf{1 3 7 . 0 6 0 . 7 0 2 , 3 4}$ \\
\hline Total patrocínio público & $\mathbf{1 6 3 . 3 1 1 . 5 3 7 , 8 2}$ \\
\hline
\end{tabular}

\begin{tabular}{|cll|}
\hline \multicolumn{3}{|c|}{ Patrocínio privado } \\
\hline Posição & Sigla da entidade & Valor (R\$ mil) \\
\hline $1^{\circ}$ & Sistel & $12.088 .261,74$ \\
$2^{\text {o }}$ & Fundação Cesp & $9.529 .741,00$ \\
$3^{\text {o }}$ & Valia (CVRD) & $6.146 .423,31$ \\
$4^{\circ}$ & Itaubanco & $5.973 .989,45$ \\
$5^{\circ}$ & Banesprev & $3.310 .734,95$ \\
$6^{\circ}$ & Telos & $2.595 .481,69$ \\
$7^{\circ}$ & HSBC & $2.243 .512,35$ \\
$8^{\circ}$ & CxUsiminas & $1.857 .735,63$ \\
$9^{\circ}$ & Funbep & $1.846 .435,84$ \\
$10^{\circ}$ & IBM & $1.832 .287,31$ \\
\hline Total 10 maiores & $\mathbf{4 7 . 4 2 4 . 6 0 3 , 2 7}$ \\
\hline Total patrocínio privado & $\mathbf{9 2 . 5 7 1 . 6 8 1 , 8 7}$ \\
\hline Total Geral (público + privado) & $\mathbf{2 5 5 . 8 8 3 . 4 0 6 , 3 6}$ \\
\hline
\end{tabular}

Fonte: Balancete Diren/Previc.

Como cuidado epistemológico, é importante registrar que a pauta de fundos de pensão restringe-se principalmente à região Sudeste do Brasil. Nas demais regiões, o debate é menos significativo. 
A Tabela 2 mostra a distribuição de fundos de pensão por região do Brasil. ${ }^{1}$

Nela é possível observar que os fundos de patrocínio público se concentram no Rio de Janeiro (18), e os fundos de patrocínio privado (153), em São Paulo. Da mesma forma, os fundos "instituídos" ou fundos sindicais estão concentrados no Estado de São Paulo.

\section{Tabela 2 - Quantidade de entidades fechadas de previdência complementar, por região e unidade da Federação - dez. 2005}

\begin{tabular}{|c|c|c|c|c|}
\hline $\begin{array}{l}\text { REGIAO } \\
\text { Unidade da Federação }\end{array}$ & $\begin{array}{c}\text { Patrocinio } \\
\text { Público }\end{array}$ & $\begin{array}{l}\text { Patrocinio } \\
\text { P riva do }\end{array}$ & In stitui dor & Tota 1 \\
\hline NORTE & 3 & 2 & - & 5 \\
\hline Acre & - & - & - & - \\
\hline Amazonas & - & 1 & - & 1 \\
\hline Amapá & - & - & - & - \\
\hline Pará & 2 & 1 & - & 3 \\
\hline Rondônia & 1 & - & - & 1 \\
\hline Roraima & - & - & - & - \\
\hline Tocantins & - & - & - & - \\
\hline NORDESTE & 17 & 17 & - & 34 \\
\hline Alagoas & 3 & - & - & 3 \\
\hline Bahia & 2 & 4 & - & 6 \\
\hline Ceará & 8 & 1 & - & 7 \\
\hline Maranhão & - & 2 & - & 2 \\
\hline Paraíba & - & 2 & - & 2 \\
\hline Pernambuco & 2 & 5 & - & 7 \\
\hline Piauí & 2 & - & - & 2 \\
\hline Rio Grande do Norte & 1 & 2 & - & 3 \\
\hline Sergipe & 1 & 1 & - & 2 \\
\hline SUDESTE & 28 & 207 & 8 & 243 \\
\hline Espírito Santo & 2 & 4 & - & 6 \\
\hline Minas Gerais & 5 & 12 & 1 & 18 \\
\hline Rio de Janeiro & 18 & 38 & 1 & 57 \\
\hline São Paulo & 3 & 153 & 6 & 162 \\
\hline SUL & 17 & 36 & 3 & 56 \\
\hline Paraná & 8 & 12 & - & 20 \\
\hline Rio Grande do Sul & 8 & 15 & - & 21 \\
\hline Santa Catarina & 3 & 9 & 3 & 15 \\
\hline CENTRO-OESTE & 17 & 15 & - & 32 \\
\hline Distrito Federal & 14 & 11 & - & 25 \\
\hline Goiàs & 2 & 2 & - & 4 \\
\hline Mato Grosso do Sul & - & 1 & - & 1 \\
\hline Mato Grosso & 1 & 1 & - & 2 \\
\hline Total & 82 & 277 & 11 & 370 \\
\hline
\end{tabular}

Dito isso, o artigo passa a apresentar os atores que compõe aquilo que a pesquisa denomina provisoriamente de "elite sindical dos fundos de pensão", bem como suas estratégias nesse processo. 


\section{Elite dos fundos de pensão}

\section{a) Luis Gushiken}

Sócio de uma empresa de consultoria, a Global Prev - exGushiken Associados - Luis Gushiken sempre atuou na área de previdência, sendo um dos responsáveis pelo projeto de reforma da previdência apresentada pelo governo do PT, em 2003. Sobre a questão, o jornal $O$ Estado de $S$. Paulo, de 26 de novembro de 2002, afirmou: "A empresa Gushiken e Associados, que pertence ao coordenador-adjunto da equipe de transição, foi quem preparou a proposta do PT (...)."

Em outra situação, o jornal Folha de S. Paulo, de 24 de outubro de 2004, comentou:

Os fundos de pensão têm como principal interlocutor, no Palácio do Planalto, o Ministro Luiz Gushiken, ex-Presidente do Sindicato Bancário de São Paulo. Durante seus três mandatos como Deputado Federal, Gushiken era sempre acionado pelos dirigentes dos fundos (...).

O mesmo tema é abordado pelo jornal O Estado de S. Paulo, de 28 de outubro de 2002: "o Presidente da Abrapp, Fernando Pimentel vê no ex-deputado federal do PT por São Paulo, Gushiken, o principal interlocutor entre os fundos de pensão e o novo Governo. 'O Gushiken conhece a real natureza dos nossos pleitos', afirmou naquela ocasião o então Presidente da Abrapp."

"Homem de muita influência no governo, participou da escolha dos nomes para os principais cargos", afirmou a revista Veja de 29 de janeiro de 2003 a respeito de Gushiken, que auxiliou na escolha de dois importantes ministros:

O da Fazenda, Antonio Palocci, seu amigo desde os anos 1970, e Berzoini, a quem apoiou no movimento sindical e ajudou a eleger Deputado Federal. Um outro amigo, Adacir Reis, ex-assessor de Gushiken na Câmara dos Deputados, assumiu a Secretaria de 
Previdência Complementar - posto de onde se controlam os fundos de pensão. (Patury, Oyama, 2003).

Comentando sobre a criação da previdência associativa, o secretário de Previdência Complementar, Adacir Reis, confirmou a influência de Gushiken: "Trata-se de uma idéia [previdência associativa] há muito defendida por Luiz Gushiken, um dos colaboradores mais influentes do Governo" (Fundos de Pensão [revista], n. 278, 2002).

No seu livro A face oculta da reforma da Previdência, Magno Mello (2003), representante do Sindilegis, grande crítico do projeto de reforma conduzido por Lula, abordou as relações entre Sérgio Rosa, Luiz Gushiken e Ricardo Berzoini:

Além de ser funcionário de carreira do $\mathrm{BB}$, Rosa pertence à ala forte do PT, que tem entre seus representantes o Secretário Geral da Presidência da República, Luiz Gushiken. Foi Gushiken quem indicou o deputado federal Ricardo Berzoini (PT-SP) para o Ministério da Previdência. Os três têm em comum a carreira no movimento bancário de São Paulo.

Segundo informações da imprensa, enquanto ministro das Comunicações, Luis Gushiken nomeou os presidentes dos três maiores fundos, a saber: Previ, Funcef e Petros. Com exceção de Wagner Pinheiro, os dirigentes dos fundos citados negaram a afirmação.

\section{b) Ricardo Berzoini}

Considerado por esta pesquisa e pelos membros do "sistema de fundos de pensão" como um dos principais personagens da previdência privada do Brasil, Berzoini é mineiro de Juiz de Fora e formado pela Faculdade de Engenharia Industrial (FEI), de São Bernardo do Campo. Mas foi em São Paulo, como bancário concursado do Banco do Brasil, que Berzoini realizou sua carreira profissional 
e política. Foi presidente do Sindicato dos Bancários de São Paulo, Osasco e Região e o primeiro presidente da Confederação Nacional dos Bancários (CNB). No ambiente do Sindicato dos Bancários foi socializado em torno de questões de previdência privada, que será uma de suas preocupações políticas como deputado.

Elegeu-se deputado federal pelo PT em 1998 e 2002. No primeiro mandato, liderou, junto com Gushiken campanhas e lobbies para a aprovação das Leis Complementares n ${ }^{0} 108$ e no 109/2001, as quais autorizam a criação e gestão de fundos de pensão pelos sindicatos. No segundo mandato, foi convidado pelo presidente Lula a ocupar a pasta da Previdência, e, posteriormente, a do Trabalho.

Como Ministro da Previdência, regularizou a previdência associativa (previdência sindical) e realizou ciclos de campanhas de esclarecimento sobre esse novo dispositivo. Juntamente com Adacir Reis, buscou a consolidação da Secretaria de Previdência Complementar no quesito transparência, e enfatizou a necessidade de despertar a educação previdenciária e financeira do brasileiro. Apontando a crise da previdência social, fez alusão aos fundos de pensão como alternativa à (in)segurança oferecida pelo Instituto Nacional de Seguridade Social (INSS).

Vale lembrar a polêmica em que Berzoini esteve envolvido, quando, ainda na pasta da Previdência, convocou idosos de mais de 90 anos a comprovar, no INSS, que ainda estavam vivos, para evitar o pagamento de benefícios indevidos. No final de 2005, com o "episódio do mensalão", foi substituído no Ministério do Trabalho por Luis Marinho (da CUT), quando passou a ocupar o cargo de secretário-geral do PT, em substituição a Sílvio Pereira, envolvido em tal escândalo.

Aqui, tem-se evidência do capital simbólico do qual dispõe Berzoini: afinal, em um momento de crise do PT, quando se fazia necessário levantar a sua credibilidade moral, foi indicado para o 
cargo de secretário-geral. Vale lembrar que, ainda em 2005, Berzoini foi escolhido como candidato oficial do Campo Majoritário à presidência do Partido, derrotando no segundo turno o opositor, Raul Pont, fato que sustenta o argumento de que dispõe de significativo capital simbólico no PT.

\section{c) Adacir Reis}

É consenso entre todos os entrevistados por esta pesquisa (sindicalistas e dirigentes de fundos de pensão) que Gushiken e Berzoini são os "empreendedores morais" do projeto dos fundos de pensão; da mesma forma, Adacir Reis é reconhecido como o portavoz dos fundos, "legítimo para falar, ouvir e agir" em nome dos membros do sistema.

Dados e evidências empíricas sugerem que Adacir Reis é tido, pelos membros do sistema, quase como um "guardião" dos fundos de pensão, não somente junto aos sindicalistas, mas também aos órgãos do sistema, como Abrapp e Anapar, onde esse ator social goza de grande confiança e prestígio.

Advogado, especialista em previdência privada, Adacir Reis organizou livros e debates em torno dos fundos, nos anos que antecederam a eleição de Lula. Amigo de longa data de Gushiken, esteve presente no primeiro mandato à frente da Secretaria da Previdência Complementar. Portanto, empreendedor moral e burocrático dos fundos, não tem medido esforços para a criação de uma nova crença em torno destes, bem como para a institucionalização e consolidação dos fundos de pensão no Brasil.

O consenso em torno do seu trabalho ultrapassa as possíveis diferenças ideológicas existentes entre os sindicalistas:

Esse rapaz é um grande profissional.Você sabe que ele é consenso no movimento sindical, já é consenso. O Adair é muito bom, ele é 
aquele incansável, aquela pessoa que abraça o tema, aquela pessoa envolvida. (Entrevistada do Banesprev).

O responsável por toda essa postura em relação aos fundos é o Dr. Adacir Reis que é uma pessoa que eu recomendo que você converse e fale até em meu nome pra ele, porque eu tenho uma admiração pelo trabalho, pela determinação, pela seriedade, pela ética, é uma pessoa qualificada e, se não fosse desse jeito, nós realmente teríamos problemas. (Entrevistado da Força Sindical).

Adacir, ao contrário de outros secretários, vem do setor, sempre foi assessor de Berzoini e Gushiken que sempre trabalharam nesta área. Foi advogado previdenciário, militava nesta área e continua. Acho que é uma pessoa que tem profundo conhecimento do sistema e tem uma visão muito clara de incentivo à previdência complementar. (Entrevistado da Anapar).

Como se pode constatar ao longo dos depoimentos, os entrevistados declararam sua legitimidade e reconhecimento à Adacir Reis, o que ficou claro por ocasião da criação da Superintendência Nacional de Previdência Complementar (Previc). Naquele momento, o presidente da Abrapp afirmou que Adacir Reis era o melhor nome para assumir a direção do órgão:

Reis vem sendo o obreiro dessa imensa construção que o governo já conseguiu colocar de pé nos últimos dois anos, dando ao sistema de fundos de pensão uma oportunidade ímpar de concretizar nos próximos anos seu enorme potencial (...) qualquer descontinuidade poderá causar prejuízo irreparável. (Diário dos Fundos de Pensão, 2005).

Sobre a direção da Previc, foi consenso entre todos os entrevistados, tanto do setor de fundos de pensão, como do setor sindicalista, que Adacir Reis era o melhor representante do sistema. Exercendo o monopólio de porta-voz, Adacir Reis conta com uma relação de cumplicidade dos participantes do sistema de fundos de pensão, o que permite que ele exerça, de certa forma autorizada, a violência simbólica (Bourdieu,1996).

Além dos nomes já citados, o governo tem outros grandes interlocutores na temática (Quadro 2). 


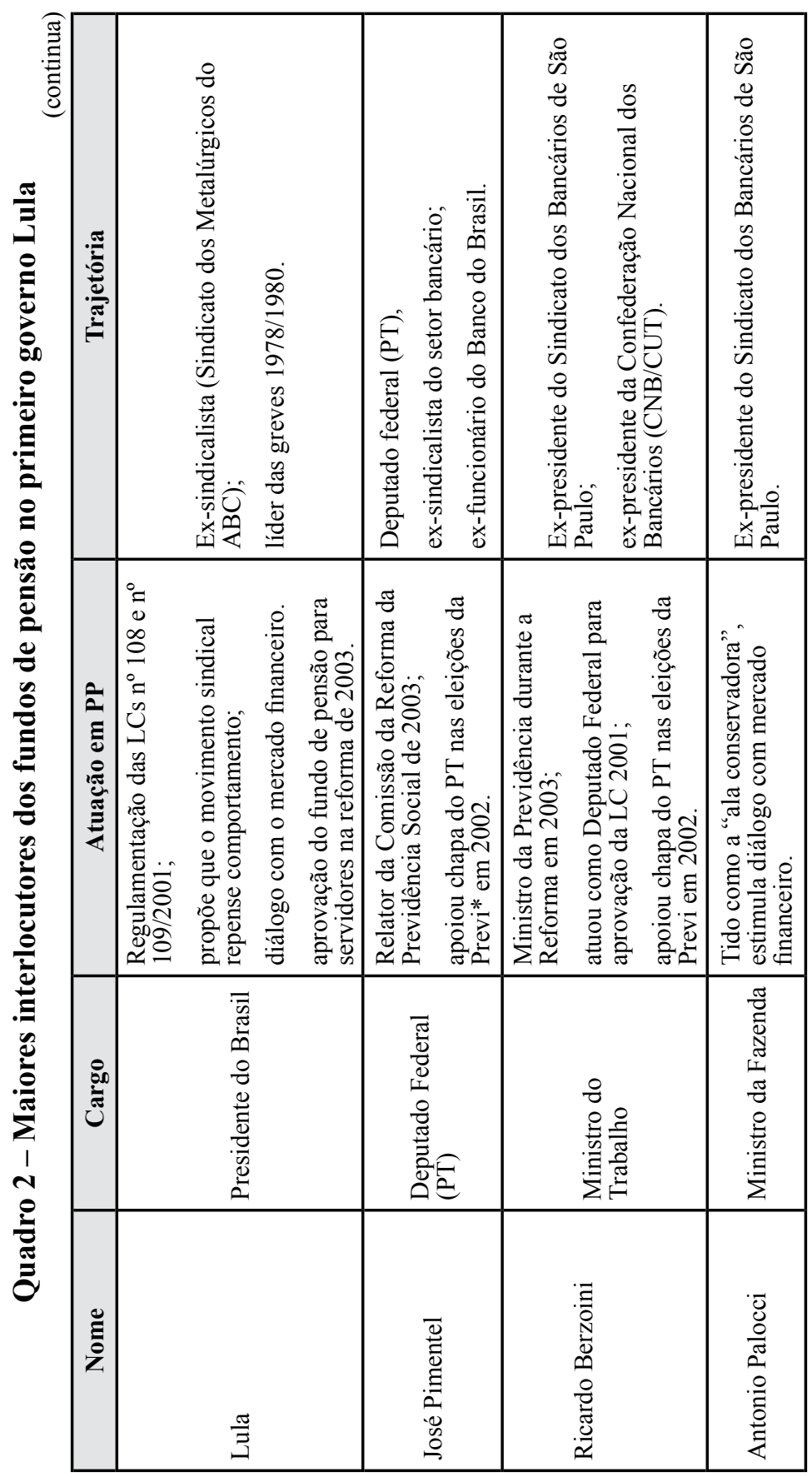




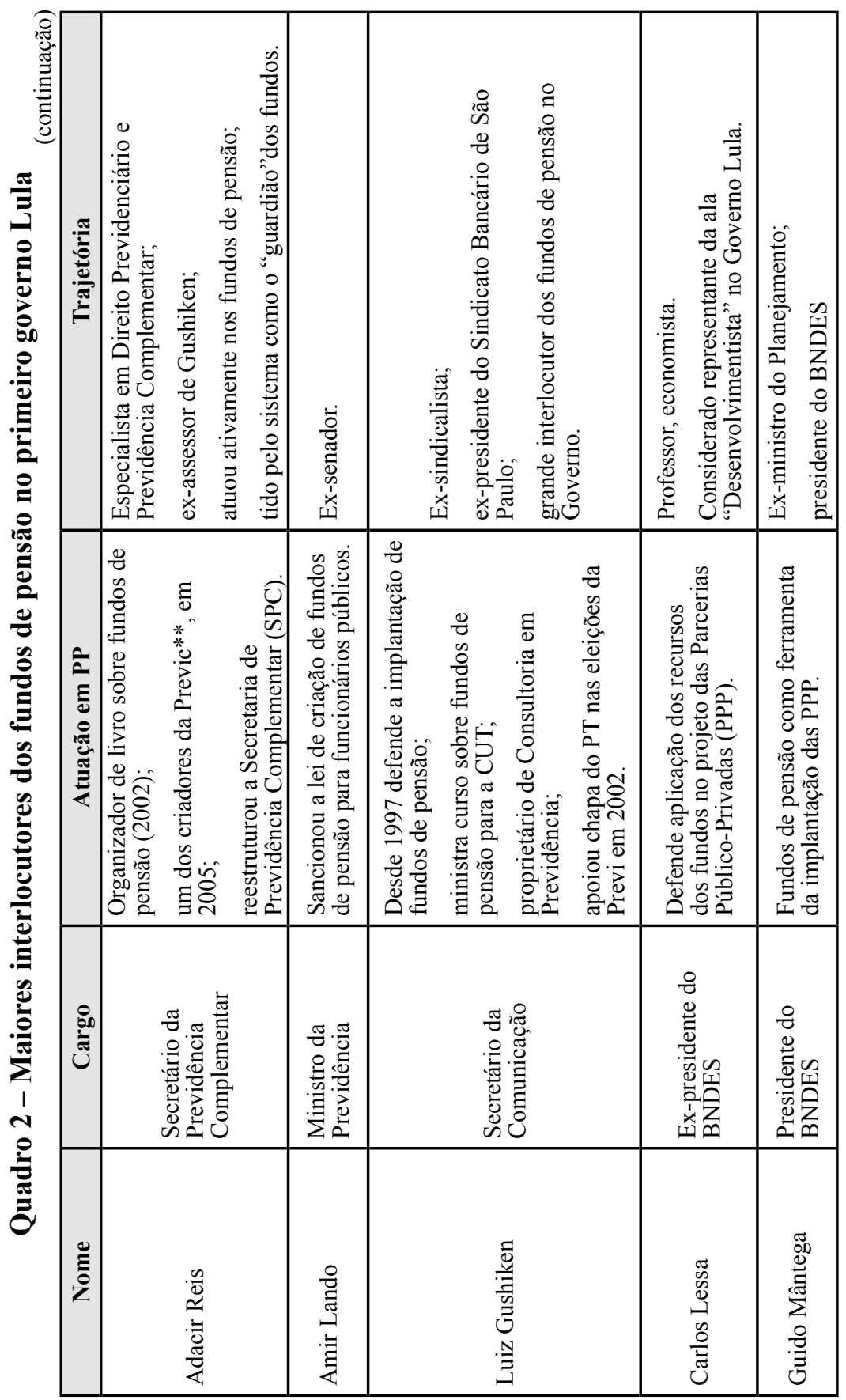




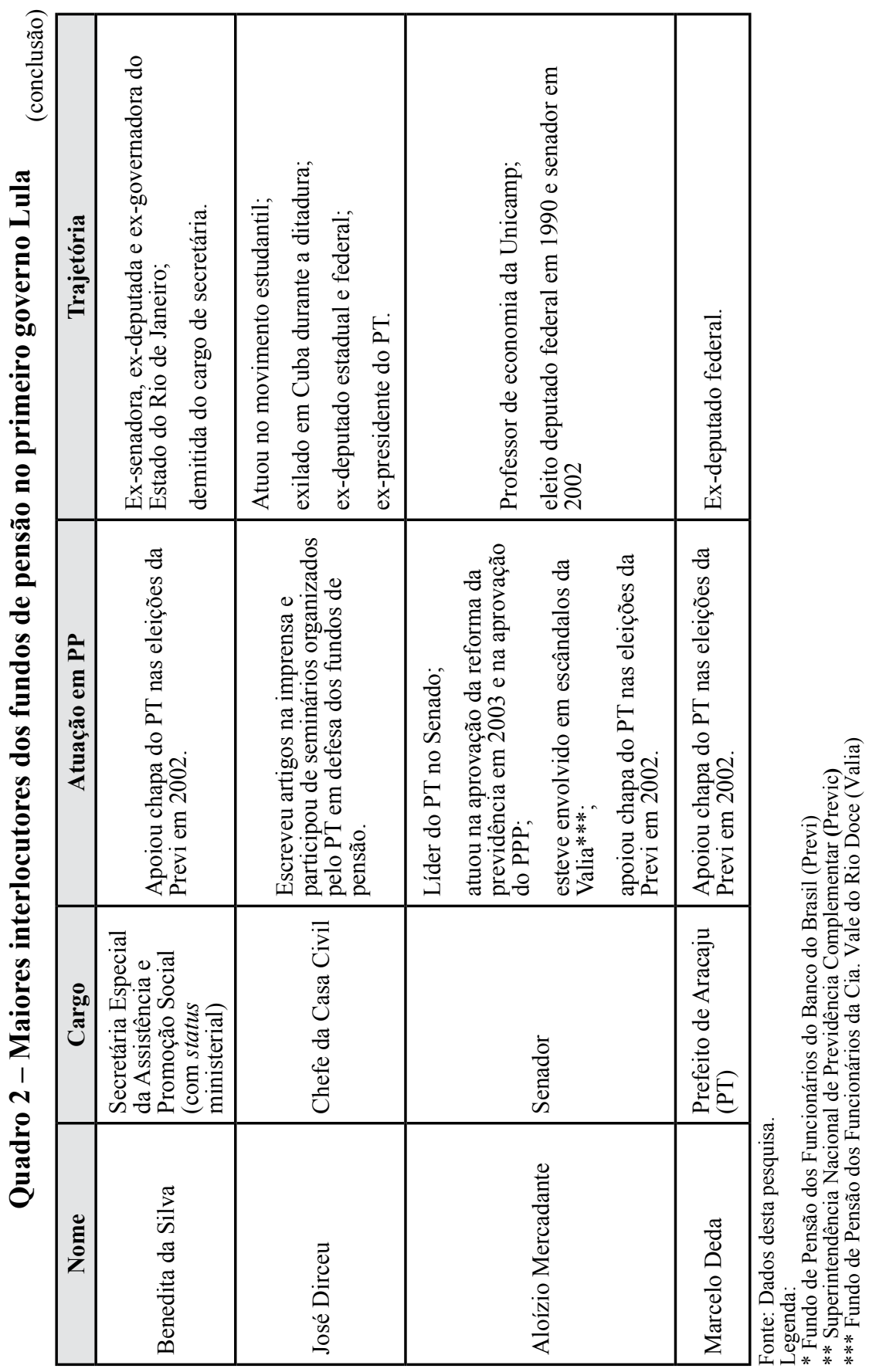


A pesquisa empírica apontou, ainda, o papel do Ministério da Previdência e da própria Secretaria de Previdência Complementar como fundamentais na consolidação dos fundos. As instituições do mercado, como Abrapp e Anapar, também foram citadas pelos entrevistados como essenciais para que os fundos pudessem ter um espaço de representação e de diálogo com o governo.

\section{"Dirigentes tradicionais" de fundos e "dirigentes sindicais": lutas e tensões}

O material empírico evidencia uma tensão no mercado de fundos de pensão entre a "vanguarda financeira", formada pelos sindicalistas que se interessam por fundos, e os "dirigentes tradicionais" dos fundos, formados pelos profissionais do mercado financeiro. Como fruto dessa tensão, os "dirigentes sindicais" precisam vencer os preconceitos dos dirigentes tradicionais dos fundos. Uma das exigências é a busca de expertise.

Essa busca passa pela necessidade de que os novos "reconvertidos" não sejam vistos como "amadores" pelos profissionais do mercado financeiro, afinal, para se fazer ouvir, é necessário falar a voz das finanças, conhecer seus códigos e, no limite, submeter-se à ordem estabelecida. Wagner (2005) identificou uma intensa busca dos sindicatos europeus por expertise, o que ela denomina "operação de desencantamento".

Importante registrar que a formação dos sindicalistas brasileiros tem inicialmente uma motivação institucional, ou seja, a Lei Complementar ${ }^{\circ}$ 109/2001 exige que o participante de Conselho Fiscal e Deliberativo ou da Direção do fundo tenha um mínimo de conhecimento técnico sobre mercado financeiro.

Além disso, a busca por novas expertises é resultado de uma tensão interna no mercado de fundos de pensão. Essa tensão busca 
definir quem é legítimo para gerir os fundos. Observa-se, assim, um conflito simbólico entre financistas e sindicalistas, entre profissionais do mercado financeiro e representantes sindicais, bem como um espaço de interlocução entre "dirigentes tradicionais" e "dirigentes sindicalistas".

Os "dirigentes tradicionais" olham com desconfiança para o profissionalismo dos "dirigentes sindicais" de fundos de pensão, já que os sindicalistas (re)convertidos são tidos por outsiders, enquanto que os "dirigentes tradicionais" seriam os "estabelecidos", no sentido de Elias (2000).

“Os outsiders" e "os estabelecidos" são termos que Elias utiliza para definir as relações em uma pequena cidade da Inglaterra, onde existe clara divisão entre um grupo estabelecido desde longa data e um grupo mais novo de moradores (os forasteiros), tratados como outsiders. Nessa pequena cidade, a exclusão social e o estigma dão a tônica na relação outsiders versus estabelecidos; como conseqüência, os forasteiros não desenvolvem o sentimento de pertencimento ao grupo.

Elias define algumas características que, segundo ele, podem ser aplicadas a todo tipo de relação outsiders-estabelecidos: "Os estabelecidos tratavam todos os recém-chegados como pessoas que não se inseriam no grupo, como "os de fora"'. Acrescenta que, com o tempo, os próprios recém-chegados passavam a aceitar, sem resignação, a idéia de pertencerem a um grupo de menor virtude. Nesse sentido, na comunidade estudada por Elias, o grupo estabelecido atribuía a seus membros características superiores, e excluía todos os membros do outro grupo do contato social. Segundo Neiburg (2000), os indivíduos que fazem parte de ambos os grupos estão, ao mesmo tempo, separados e unidos por um laço tenso e desigual de interdependência.

Este artigo sugere que é no contexto de outsiders e estabelecidos que é possível imaginar a tensão existente entre 
"dirigentes tradicionais" e "dirigentes sindicais", que ora disputam e ora compartilham a configuração precisa em torno dos fundos de pensão no Brasil.

Além da tensão exposta acima, o material empírico evidenciou um outro tipo de tensão: um desconforto entre os próprios sindicalistas, ou seja, os sindicatos denominados provisoriamente como "vanguarda financeira" (criadora/gestora dos fundos de pensão) e os sindicalistas que continuam na pauta tradicional de luta, chamados aqui, provisoriamente, de "sindicatos tradicionais".

Para os "sindicalistas tradicionais", as lutas sindicais acontecem em torno do desemprego/emprego, flexibilização das condições de trabalho, jornada de trabalho, dentre outros. Os "sindicalistas tradicionais" acham que os sindicatos da "vanguarda financeira" não respeitam os antigos valores do grupo. A agenda dos fundos de pensão rompe com o sentimento de pertencimento, o que traduz uma tensão evidente entre os "sindicatos tradicionais" e os sindicatos da "vanguarda financeira". "Os velhos sindicalistas não vêem com bons olhos esta mudança de agenda e olham com desconfiança" (entrevistada da CUT), a postura dos “(re) convertidos". Portanto, os "(re)convertidos" existem na e pela diferença que os separa (Bourdieu, 1996) dos "sindicalistas tradicionais".

Em entrevista, por e-mail, com sindicalistas de Pernambuco e do Rio Grande do Sul, foi possível saber que as pautas desses sindicatos ainda são jornada de trabalho, salário e condições de trabalho. Acrescentaram que conhecem o debate sobre fundos de pensão, mesmo que este não seja, ainda, a agenda principal dos sindicatos. Assim, o discurso de alguns sindicatos de base é diferente do discurso oficial das centrais.

O conflito entre sindicatos que defendem e aqueles que não defendem as "modernas" pautas, tais como fundos de pensão, diálogo com mercado financeiro e capitalismo acionário, é uma questão a ser trabalhada em investigações futuras. 
Em pesquisa sobre os trabalhadores do $\mathrm{ABC}$ paulista, Tomizaki (2006) mostra que os processos de sucessão são vividos de forma contraditória, tanto por aqueles que transmitem suas posições, como pelos que, como herdeiros de um determinado espaço social e simbólico, sentem-se chamados a dar continuidade a um projeto que pode ser pessoal, familiar, profissional ou político. A autora afirma que existe uma disputa em torno da herança política da categoria. Pode-se sugerir que é a herança política da categoria que leva à tensão entre "vanguarda financeira" (sindicalistas que defendem os fundos de pensão) e "sindicatos tradicionais" (que defendem pautas tradicionais de luta).

A idéia de reconversão pode ser pensada, também, pelo viés bourdiano de "revolução simbólica", no sentido que supõe uma revolução mais ou menos radical dos instrumentos de conhecimento e das categorias de pensamento. Frisa-se que uma revolução simbólica significa uma ruptura com um estado de um sistema e muda o princípio da visão e divisão do mundo. Segundo Bourdieu (1996b), as revoluções simbólicas ${ }^{2}$ são, sem dúvida, aquelas que, mais do que o conformismo moral, ofendem o conformismo lógico uma vez que promovem mudança nas estruturas mentais e no conjunto de percepções dos agentes.

\section{A estrutura social do campo auxilia na reconversão}

Observou-se, durante pesquisa de campo, que a própria estrutura social do campo interfere na "(re)conversão" dos sindicalistas. O surgimento de instituições como o Instituto Ethos, responsável pela responsabilidade social, e do Instituto Brasileiro de Governança Corporativa (IBGC) fazem parte da institucionalização dos fundos de pensão.

Essas instituições, legitimadas para falar e ouvir, buscam uma interlocução com a sociedade, a grande imprensa e a imprensa 
de negócios. E, ainda, com outros atores sociais, tais como ONGs, comunidades de bairro e universidades, onde acadêmicos dão suporte intelectual para a temática.

Buscando alargar as relações e concretizar alianças por meio dessas e de outras instituições, o sistema prevê a necessidade de parceria com universidades, centros de pesquisa, instituições do mercado financeiro, associações e centrais sindicais. Em universidades e centros de pesquisa foram criados prêmios e concursos de monografias, visando aproximar a academia do tema. Discursivamente, o objetivo é buscar, em conjunto com o governo, com a sociedade e com as universidades, alternativas possíveis para o desenvolvimento do país. O Prêmio Ethos de responsabilidade social e o prêmio sobre governança corporativa do IBGC, realizados anualmente, são bons exemplos. Há ainda prêmios patrocinados pela Bovespa.

Conforme material empírico desta pesquisa, a (re)conversão sindical e a formação de uma "nova elite dirigente dos fundos de pensão" foram encarnados pelas instituições do mercado financeiro e pelo governo. Desse modo, o governo petista se pronunciou sobre sua "nova" agenda e convidou as centrais e sindicatos a participarem dela. A TV divulgou suas idéias; a mídia de negócio passou a propagar um "novo" capitalismo, baseado na ética e na moral, os auditores se envolveram, e as consultorias se tornaram mediadoras dos cursos de fundos de pensão, produzindo e ensinando aos sindicalistas uma linguagem própria da gestão.

Portanto, visando divulgar e consolidar o espaço social dos fundos de pensão, o governo tem realizado eventos de grande importância, tais como seminários nacionais, regionais e internacionais, distribuição de cartilhas informativas e mesasredondas para reunir os principais atores do processo, esclarecêlos, orientá-los e formá-los na criação/gestão dos fundos de pensão, especialmente junto aos sindicatos. Portanto, impulsionados pelo 
governo, os membros do "sistema" têm papel ativo na construção e reprodução das crenças que ajudam a definir configurações e convenções em torno dos fundos de pensão.

Importante enfatizar que é na polissemia de diversas vozes e diversos discursos, bem como na assimetria de informações, onde dialogam diversos e distintos atores sociais ao mesmo tempo, que a construção de novas convenções sociais em relação ao mercado de fundos de pensão acontece. Aceitar e defender conceitos tais como investimento ético, responsabilidade social e governança corporativa não significa, necessariamente, ter conhecimento sobre o assunto. Houve casos em que os entrevistados não entendiam bem a proposta dos fundos de pensão, mas defendiam-na. A polissemia pode ser aplicada aos fundos de pensão justamente porque cada ator entende o conceito de acordo com sua visão de mundo particular. $\mathrm{O}$ conceito de polissemia pode ser entendido ainda como "uma conversa" com diversidade de significados para cada grupo social que dela participa.

Via fundos de pensão (Jardim, 2008), ocorre toda uma movimentação significativa em torno da "moralização" "domesticação" do capitalismo. É importante destacar que este artigo não está interrogando se a realidade social mudou ou não. O que se pretende mostrar é a construção social em volta do tema, pontuando atores sociais de forma a detectar as energias sociais de que dispunham nossos atores envolvidos na temática.

\section{Papel da CUT}

Visando formar os sindicalistas na temática dos fundos de pensão e em torno dela construir uma realidade social, centrais sindicais têm investido na formação de seus gestores. Segundo informantes ligados à CUT, nos anos de 2000, 2001, 2002 e 2003, ela ministrou o curso de formação em Previdência complementar e 
regime próprio, com apoio do Dieese e do Ministério do Trabalho. Para tanto, contou com apoio da consultoria Gushiken Associados, ${ }^{3}$ especialista em previdência, do ex-Secretário de Comunicação do governo Lula.

O objetivo do curso foi preparar o movimento sindical para atuar na criação e gestão dos fundos de pensão, fornecendo suporte aos sindicalistas nas questões relativas à criação de um fundo de pensão e na elaboração da carteira de investimento do fundo. Ressalta-se que Gushiken tem sido o mediador da formação interna nos sindicatos.

Convém lembrar que, na busca de formação da "nova elite", os rituais servem tanto à socialização dos membros do "sistema", quanto ao princípio de que os fundos são capazes de promover solidariedade e reciprocidade entre as gerações; assim, coquetéis, festas e congressos nos finais de semana em (luxuosos) hotéisfazenda se tornam um ritual de auto-legitimação, bem como eventos necessários para delimitar, fixar e fortalecer as percepções de nossos atores no que se refere aos fundos de pensão. Assim sendo, cumprem o papel de reforçar discursos e práticas, propiciando a naturalização dessa nova convenção social (Douglas, 1998).

Uma sindicalista fala dos cursos e das parcerias com o Dieese e com a Consultoria de Luis Gushiken:

Nós fizemos alguns cursos para qualificação dos dirigentes; teve um curso que foi inclusive do FAT. A gente fez cursos aqui sobre fundos de pensão, eles deram o curso para gente, não necessariamente o Gushiken, mas naquela época era a Gushiken Associados; então eles deram um curso junto com o Dieese, nós cedemos o espaço, fizemos aqui no sindicato, eram vários sindicalistas, não eram só os bancários, mas participantes também, porque era para explicar como eram os fundos de pensão, como foi criado... tudo isso era para você inserir o dirigente sindical dentro desse debate, que, por exemplo, nós da Nossa Caixa, a gente já discutia, mas também não sabia como funciona essa coisa atuarial. (Entrevistada do Sindicato dos Bancários de Campinas). 
A CUT tem promovido, ainda, diversos seminários de formação em previdência complementar e reforma da previdência social. Nesses, conta com o apoio de acadêmicos como Ricardo de Medeiros Carneiro (Unicamp), Carlos Schimidt (UFRGS), Laura Tavares Soares (UERJ), dentre outros. É importante registrar que a Federação dos Bancários de São Paulo fez convênio com a Globalprev para que esta consultoria (empresa de Luis Gushiken) seja a responsável pela formação em fundos de pensão do setor bancário.

Em 2003, a Anapar organizou cursos sobre fundos de pensão e previdência complementar em parceria com a AFL-CIO e que foram ministrados pela Globalprev. O objetivo foi aprofundar aspectos da atuária. $\mathrm{O}$ público-alvo eram os dirigentes/entidade de classe (sindicatos e associações de participantes). Vale esclarecer que a qualificação dos sindicalistas ligados à Força Sindical tem o apoio do Dieese e da Central norte-americana, a AFL-CIO.

Em 2004 houve um programa de treinamento realizado pelo consultor Tadeu Ferrari (da Globalprev), também direcionado aos sindicalistas. Durante o curso, houve o lançamento de vários livros sobre a temática. ${ }^{4} \mathrm{O}$ seminário "Fundos de pensão como combate ao capital especulativo" também fez parte do mesmo processo.

Os entrevistados declaram a necessidade dos cursos, tendo em vista a complexidade do assunto. Tanto os sindicalistas da CUT quanto o da Força Sindical utilizaram o adjetivo "árido" para se referir à complexidade do assunto (fundos de pensão). Isso pode sugerir uma "educação" homogênea em fundos de pensão, já que os "educadores", a "elite sindical dos fundos de pensão", trabalha de forma implícita e explícita na criação de convenções sociais (Douglas, 1998) acerca dos fundos junto ao movimento sindical.

A preocupação com formação é grande (...) o debate é novo e o assunto é um pouco árido, então vem a dificuldade de pessoal 
qualificado até para ministrar os cursos (...) a CUT está preocupada em qualificar cada vez mais trabalhadores para que eles possam ser não só dirigentes, como também para estar entendendo, reivindicando, acompanhando. Porque se você não entende você também não cobra. Precisa formar massa crítica que fique de olho no assunto. (Entrevistado da Banesprev).

É uma matéria muito árida. Não é uma matéria tranquila de se perceber. Nós estamos falando com uma certa tranquilidade de questões sociais, mas a instrumentalização dessa atividade é altamente técnica. Nós vamos ter banco, vamos ter gestor, vamos ter profissionais que tenham essa capacidade. [É necessário] não só essa sensibilidade de perceber o alcance de uma atividade que é complexa. (Entrevistado da Força Sindical).

Assim sendo, o papel das consultorias de fundos de pensão é fundamental no contexto de formação dos sindicalistas. A Globalprev cumpre um importante papel junto ao movimento sindical. Como mais um dado ilustrativo, em 2005, técnicos da Globalprev ministraram curso sobre o PrevMais, plano de previdência complementar do Economus, na modalidade de contribuição definida. Segundo palavras do jornal $O$ Bancário, de 10 de fevereiro de 2005, o técnico da Globalprev "destacou a importância da previdência complementar, principalmente no modelo de previdência fechada, onde uma das principais vantagens em relação aos modelos de mercado é a contribuição do banco, e em igual valor ao do funcionário, ou seja, $8 \%$ do salário."

Tendo em vista que os segmentos sindicais se deslocam do seu legítimo campo de atuação, o espaço político/trabalhista, em direção a um espaço em que são considerados outsiders, o espaço econômico/financeiro, pode-se compreender a preocupação dos sindicatos com a formação de seus membros. É uma resposta ao discurso dos financistas, que, apoiados no argumento da expertise, defendem que são os legítimos gestores dos fundos, já que possuem formação técnica para tal, em detrimento dos sindicalistas, os quais não compartilham dos códigos do mercado financeiro. 
Como consequência dessa luta simbólica pela definição de quem é legítimo na administração dos fundos de pensão, os dirigentes sindicalistas sofrem violência simbólica, expressa claramente em forma de preconceito. "Nós, que somos profissionais do mercado, fazemos melhor do que o pessoal ligado aos sindicatos" (entrevistada do Banesprev), ${ }^{5}$ é o argumento que busca equilibrar as relações de força em favor dos dirigentes tradicionais.

O presidente da Anapar, José Sasseron (2002, p. 175), falou do preconceito que sofrem os sindicalistas:

Um dos argumentos sempre utilizados para questionar a participação dos trabalhadores nas entidades de previdência, sobretudo no que tange aos investimentos, é sua falta de preparo técnico. Esse argumento revela um preconceito profundo: o trabalhador é capaz de gerar riqueza, mas não teria capacidade para gerir seus recursos, que devem ser entregues a terceiros. A única barreira intransponível para vencer esta questão é o preconceito: se de fato os participantes têm deficiências técnicas, elas podem rapidamente ser sanadas pela simples presença nos cursos, faculdades e centros de formação que proliferam pelo Brasil afora.

Sobre a relação de preconceito, a entrevistada da Banesprev contou que os dirigentes tradicionais justificam que eles possuem maior capacidade técnica para gerir os fundos de pensão do que os dirigentes sindicalistas, sem formação em finanças:

Pesa certo preconceito com o trabalhador na gestão. Imagina trabalhador na gestão, a gente aqui é do mercado e o mercado consegue fazer melhor que o pessoal do sindicato, muito melhor porque somos profissionais do mercado. Tem um preconceito grande. Dá então um debate enviesado quando se fala que o pessoal do sindicato não tem formação para administração e não é bem assim. Não quer dizer que todo pessoal que está no sindicato pode trabalhar com fundo de pensão, mas tem quem pode (...) até porque a lei exige que tenha qualificação para fazer parte do conselho. (Entrevistada do Banesprev).

A violência simbólica sofrida pelos dirigentes sindicalistas tem origem no conhecimento técnico dos dirigentes tradicionais de 
fundos. Esse tipo de violência simbólica é definido por Bourdieu como Dominação Institucionalizada, uma vez que é exercida por meio de conhecimento formal adquirido na escola. No sentido de Bourdieu (2000), a escola consagra uma divisão social préexistente.

Como sugere Bourdieu (1996a), a teoria da violência simbólica se apóia em uma teoria da crença, ou melhor, em uma teoria da produção da crença, do trabalho de socialização necessário para produzir agentes dotados de esquemas de percepção e de avaliação que lhes farão perceber as injunções inscritas em uma situação.

Acrescenta que a violência simbólica é aquela violência que "conquista" submissões sequer percebidas como tais, apoiandose em crenças socialmente construídas. Segundo Bourdieu, para que a violência simbólica ocorra é necessária a cumplicidade do dominado, que fica clara no discurso sindical, uma vez que este passa a reproduzir a crença da qualificação:

Se você não se qualificar para este debate, alguém vai ocupar o espaço. [...] o fundo de pensão é atrativo, mas você tem que ter dentro da entidade pessoas que vão tocar isso, tem que ser especialista nisso. (Entrevistado do Sindicato dos Bancários de Campinas).

Faz uns três anos que nós formamos a comissão da diretoria de interior do banco, mas nós só conseguimos ganhar esse debate com a assessoria da Globalprev, que fez uma proposta para gente, porque você precisa ter seu técnico, não adianta você chegar lá, se não tiver uma gente especializada [sic] para fazer o debate com você, não dá certo. (Entrevistado do Sindicato dos Bancários de Campinas).

Nessa luta cognitiva, ${ }^{6}$ para definir quem é legítimo na gestão de fundos de pensão, o presidente da Anapar, lembrou o capital político dos sindicalistas, o que lhes dá legitimidade para a administração dos fundos de pensão:

$\mathrm{O}$ bem maior que um representante eleito pelos participantes leva à gestão dos fundos é seu compromisso com a defesa dos interesses 
daquela coletividade. Esse compromisso não se aprende na escola, mas na relação política diária, mediada pelas organizações e entidades de classe. (Sasseron, 2002, p.175).

O sindicalista da CUT, Altemir Antonio Tortelli, escreveu na apostila do curso de formação em Previdência complementar e regime próprio sobre a necessidade de formação do movimento sindical nas questões de fundos de pensão:

Nós, dirigentes da CUT, detectamos que o conhecimento sobre o funcionamento dessas novas estruturas previdenciárias ainda é restrito a poucos setores do sindicalismo, fato que, não raras vezes, coloca o sindicalista em posição de desnecessária inferioridade em relação aos seus empregadores (...) Por tudo isso, temos a certeza de que a implantação dos referidos cursos de formação contribui para tornar o movimento sindical mais apto na luta por uma previdência justa, capaz de oferecer tranquilidade futura aos trabalhadores. (Gushiken Associados, 2002).

Finalmente, observou-se nesse item que os sindicatos despontam como importantes interlocutores do mercado financeiro, estendendo seu campo de ação para além do espaço sindical tradicional. Para tanto, fazem uso da profissionalização para se legitimarem como representantes dos fundos.

Nesse processo, que pode ser chamado de depuração/afirmação e conquista de visibilidade social, os “dirigentes sindicalistas" buscam nitidamente se diferenciar dos "dirigentes tradicionais" dos fundos de pensão. É bom lembrar que os ensinamentos de Bourdieu (1996a) mostram que é na distinção que os grupos existem socialmente, ou seja, os "grupos existem na e para a diferença".

\section{Reconversão, institucionalização e profissionalização do setor: educação financeira}

No processo dessa reconversão, existe uma "elite” vanguardista responsável pela criação e/ou apropriação de novas convenções 
sociais, no que se refere ao capitalismo brasileiro contemporâneo, bem como pela "educação da sociedade" quanto ao "uso prudente" do dinheiro.

Reflexos desse processo de "dominação das finanças" é o surgimento no mercado de diversos consultores, que se colocam como "gurus" do uso "inteligente" e "racional" das finanças. Além disso, o mercado e o Estado começam a colocar em pauta a educação financeira no Brasil. $\mathrm{O}$ argumento dos atores interessados na educação financeira da sociedade é que ignorar os códigos do mercado se tornou uma outra forma de exclusão social, haja vista "o poder das finanças". Assim, sem "cultura financeira", os trabalhadores ficariam reféns do mercado de capitais.

No material produzido pelo mercado financeiro, os profissionais reclamam da ausência da educação financeira nos brasileiros. O consultor em Previdência da OCDE e ex-secretário Nacional da Previdência Social, Vinícios Pinheiro, fala da importância de um Programa de Educação Financeira no Brasil:

Assim como se fazem campanhas como as de vacinação, dirigidas a um público específico, onde se explica através de cartilhas a importância daquela campanha, o processo de educação financeira é semelhante a essas campanhas, já que os participantes dos fundos estariam se vacinando contra prejuízos futuros. (Fundos de Pensão [revista], 38, n. 296, 2004).

Bárbara Smith, financista da OCDE, argumenta que a educação financeira é fundamental para os consumidores, no sentido de que pode ajudá-los a estabelecer metas orçamentárias e gerenciar a renda, de modo a maximizar o retorno sem se tornarem vítimas de fraudes. Para Smith, as pessoas educadas financeiramente são mais confiantes para participar de processos decisórios, como a escolha de seus investimentos; contudo, "as pessoas relutam em se interessar por programas de educação financeira" (Fundos de Pensão [revista], 38 , n. 296, 2004). 
Os entrevistados enfatizam a falta de cultura do trabalhador em participar do mercado financeiro:

Se a gente tivesse uma cultura aqui de investir [sic] em ações das empresas para o trabalhador, o que ia acontecer? As empresas seriam mais alavancadas, as empresas criariam mais vagas, mais postos de trabalho, as empresas se dariam muito melhor se elas conseguissem se financiar com o capital acionário de compra de ações de diversos agentes do mercado do que se ela tivesse que ficar pendurada nos bancos, com empréstimos a taxas que a gente já conhece. (Entrevistado da Banesprev).

É importante lembrar que, numa sociedade em que se registram altos níveis de analfabetismo, falar em educação financeira pode soar como ironia aos desprevenidos. Contudo, essa agenda faz sentido, diante das novas convenções do capitalismo brasileiro, que buscam a inclusão das classes populares via mercado financeiro.

O novo espaço criado em torno da consultoria movimenta o setor, produz emprego e dá legitimidade ao tema. Em parceria com institutos públicos e privados, promovem seminários, cursos, congressos, intercâmbios internacionais, entre outros eventos. A PUC-Rio oferece um curso de previdência privada, onde um dos itens é trabalhar justamente a educação financeira. Alguns desses eventos mostram o estágio de evolução do "campo", como é o caso do curso de pós-graduação lato sensu da Faculdade de Direito da Universidade Estadual do Rio de Janeiro (UERJ). ${ }^{7}$ Da mesma forma, a criação de revistas e de órgãos para dar legitimidade ao sistema, como a revista da Anapp, na UERJ, faz parte do mesmo processo.

O sistema de fundos de pensão entende a necessidade de parceria com universidades, centros de pesquisa, instituições do mercado financeiro, associações e entidades ligadas ao sistema. $\mathrm{O}$ Instituto Cultural de Seguridade Social (ICSS) defende a criação de uma universidade que dê formação em Previdência Complementar, visando profissionalizar a formação de recursos humanos no sistema. Segundo Arnaldo Niskier, presidente da entidade, já foram 
contatados diversos sindicatos e outras instituições do mercado visando esse objetivo:

Embora o projeto ainda não esteja pronto para ser apresentado ao Conselho Nacional de Educação, temos conversado extraoficialmente com o secretário Adacir Reis, que revela forte desejo de melhorar os quadros com os quais o Brasil trabalha em previdência complementar e tem simpatia pela idéia. (Fundos de Pensão [revista], 38, n. 296, 2004).

No Brasil, o governo federal também tem trabalhado nessa direção. Segundo dados coletados em pesquisa de campo em Brasília, a Secretaria da Previdência Complementar distribuiu, em 2005, cerca de dois milhões de exemplares da cartilha Conheça os fundos de pensão. Nessa cartilha, foi abordada a formação de uma cultura previdenciária por intermédio dos sindicatos, pois "a criação de planos de previdência por sindicatos e demais entidades associativas contribuirá para construir no país uma cultura previdenciária cada dia maior [...]" (Brasil, 2003, p. 7). Ainda como parte das estratégias para consolidar o espaço de fundos de pensão, o governo tem premiado monografias que se interessam pelo tema.

Sobre o caso brasileiro, Berzoini (2003) enfatiza a necessidade de trabalhar a educação financeira e/ou previdenciária do brasileiro: "Educação previdenciária se faz de várias maneiras, inclusive por meio de um processo de relacionamento da previdência com a sociedade civil, que infelizmente não foi dos melhores no último ano."

Da mesma forma, nas entrevistas realizadas e no material coletado na imprensa, nos sindicatos e órgãos do sistema foi detectada a preocupação com a ausência de "cultura financeira" e/ou "cultura previdenciária" dos brasileiros. O presidente da Anapar declarou:

Eu acho que falta um pouco de cultura de previdência, falta informação também, pois acredito que a maioria dos sindicatos nem 
sabe que esta possibilidade existe e outro problema é o nível de renda da sociedade brasileira. (Entrevistado da Anapar).

Contudo, o governo tem buscado formar, orientar e propagar o mercado de fundos de pensão. Dentro de suas estratégias, encontrase a preocupação com a profissionalização do setor, uma vez que tem procurado se aproximar de centros de pesquisa e de universidades. Ao mesmo tempo em que possibilita formação técnica em previdência privada, ganha legitimidade em outro campo de atuação, ou seja, o acadêmico.

Pode-se observar que, ao estimular a criação e gestão de previdência associativa nos sindicatos, o governo tem exigido uma nova postura comportamental do sindicalismo brasileiro, evidenciando que este deve se utilizar dos fundos de pensão como uma bandeira de inclusão social dos trabalhadores. Como dito anteriormente, no Brasil, o processo inicia-se no setor bancário e, aos poucos, estende-se para as demais categorias sindicais, especialmente aquelas oriundas de ex-estatais: petroleiros, eletricitários, telefônicos e outros.

Finalmente, importa registrar que o fenômeno de criação de fundos de pensão via sindicato não é um fenômeno isolado do Brasil. Faz parte de um contexto de globalização das finanças e de predomínio do mercado financeiro sobre a produção. $\mathrm{O}$ interesse de sindicatos por fundos de pensão iniciou-se nos Estados Unidos, passando pela Europa e pelo Canadá. Essa discussão foi aprofundada na tese de doutorado da autora (cf. Jardim, 2007).

\section{Considerações finais}

$\mathrm{O}$ artigo apresentou o mapeamento da "elite sindical dos fundos de pensão", pontuando os "líderes e/ou empreendedores morais" do projeto de forma a resgatar suas trajetórias sociais e 
profissionais. Mostrou, ainda, como acontece a reconversão dos sindicalistas, e as tensões e relações de força entre aqueles que não se (re)converteram aos fundos de pensão. O preconceito em relação aos "dirigentes sindicais" é uma forma de exclusão dos "dirigentes tradicionais". Isso evidencia a violência simbólica como estratégia de manutenção do poder de gestão dos fundos de pensão.

Por sua vez, a educação financeira e a educação previdenciária fazem parte do processo de reconversão e de socialização em torno dos fundos, onde uma "elite" ensina/orienta a fazer "uso prudente" do dinheiro e das finanças.

Com os dados apresentados neste artigo, pode-se sugerir que a política de fundos de pensão tem mostrado que, ao mesmo tempo em que o segmento financeiro comanda a política do Brasil, sindicalistas, ex-sindicalistas e membros do PT fazem parte dessa "nova elite" que comanda os fundos de pensão e alguns postoschaves do mercado financeiro. Nesse sentido, é possível falar em diálogo e convergência de interesses entre a "elite sindical" e "elite financeira". É possível falar, ainda, em mudança do conceito de "mercado financeiro" no Brasil, já que este passou a incorporar preocupações da agenda social, tais como ética, investimento sustentável, transparência, justiça social, direitos humanos, etc. Aqui, cabe lembrar que a incorporação de preocupações sociais na agenda financeira é um fenômeno internacional.

Finalmente, é possível concluir que, embora detenham poder limitado nos conselhos dos fundos, determinados sindicalistas tornam-se, em certa medida, atores coadjuvantes do capitalismo contemporâneo brasileiro. Portanto, mesmo que de forma limitada, os sindicatos fazem parte dos processos decisórios e ajudam a (re) configurar os destinos do "novo" capitalismo brasileiro, promovendo mudanças nos espaços políticos e sociais. 


\section{Notas}

1 Uma pesquisa mais detalhada sobre a relação entre a concentração de fundos e as regiões brasileiras deve ser realizada futuramente pela autora.

2 Para aprofundamento do conceito de "revolução simbólica", ver Bourdieu (1996b).

3 A consultoria em previdência "Gushiken \& Associados", fundada pelo ex-secretário de Estado e Comunicação, Luiz Gushiken, teve sua razão social alterada em 22 de janeiro de 2003 para "Globalprev Consultores Associados”, logo após a indicação de Gushiken para o citado cargo.

4 O livro Regime próprio de previdência dos servidores: como implementar? Uma visão prática e teórica (Gushiken et al., 2002), foi lançado durante o curso.

5 Depoimento da entrevistada do Banesprev; segundo ela é assim que os "dirigentes tradicionais" argumentam.

6 Bourdieu refere-se à "luta cognitiva" como uma luta teórica e prática pelo poder de impor a visão legítima do mundo social (cf. especialmente Meditações pascalianas, p. 226). O uso da violência simbólica faz parte das estratégias utilizadas na "luta cognitiva".

7 O curso denominado Previdência: regimes públicos e privados, busca formar gestores dos fundos. Tem apoio da Universidade Estadual do Rio de Janeiro e iniciou-se no primeiro semestre de 2005.

\section{A "new" elite in Brazil? Unionists and former unionists at the} financial market

Abstract: The paper approaches about a possible formation of a "new" elite in Brazil. This elite has been formed by the union, which is currently linked to the financial market. The methodology adopted were interviews with trade unionists, former trade unionists and pension funds leaders and the recovery of the life history of 
certain social actors considered key figures in the Brazilian pension funds. It is suggested that there has been a conversion of certain trade unionists, because they are talking with the financial market about the pension funds themes. As a result, one evidences different tensions and disputes between trade unionists, who are interested in a pension fund (leading financial) and trade unionists, who reject the new union strategy (traditional unionists).

Keywords: "trade union elite"; traditional unionist; leading finance; pension funds.

\section{Referências bibliográficas}

BANCÁRIO, Revista dos Bancários (O), n. 1007, 10 fev. 2005.

BECKER, H. S. Outsiders: studies in the sociology of deviance. New York: The Free Press of Glencoe, 1963.

BERZOINI, Ricardo. A reforma necessária. In: MARQUES, Rosa Maria et al. (Orgs.). A previdência social no Brasil. São Paulo: Fundação Perseu Abramo, 2003. Cap. III, p.99-119.

BOURDIEU, Pierre. Les structures sociales de l'économie. Paris: Seuil, 2000.

. Meditações pascalianas. Rio de Janeiro: Bertrand Brasil, 1963.

. Razões práticas: sobre a teoria da ação. Campinas: Papirus, 1996a.

. As regras da arte. São Paulo: Companhia das Letras, $1996 \mathrm{~b}$.

BRASIL. Secretaria de Previdência Complementar. Previdência complementar: plano de instituidor. Brasília: MPS 2003. Disponível em: $<$ http://www1.previdencia.gov.br/docs/pdf/spc_cartilha instituidor.pdf $>$.

DIÁRIO DOS FUNDOS DE PENSÃO, 2005. 
DOUGLAS, Mary. Como as instituições pensam. Trad. de Carlos Eugênio Marcondes de Moura. São Paulo: EDUSP, 1998.

ELIAS, Norbert; SCOTSON, John L. (Orgs.). Os estabelecidos e os outsiders: sociologia das relações de poder a partir de uma pequena comunidade. Rio de Janeiro: Zahar, 2000.

ESTADO DE S. PAULO (O) [jornal], 26 nov. 2002.

FOLHA DE S. PAULO, [jornal], 24 out. 2004; 28 jan. 2005.

FUNDOS DE PENSÃO [revista], n. 278, nov. 2002; n. 296, jul./ago. 2004

GUSHIKEN, Luiz et al. Regime próprio de previdência dos servidores: como implementar? Uma visão prática e teórica. Brasília: MPAS, 2002. (Coleção Previdência Social, v. 17).

GUSHIKEN \& ASSOCIADOS. Previdência complementar e regime próprio. Indaiatuba: Instituto Integrar, 2002. (Apostila do curso de formação).

JARDIM, M. C. Nouvelles stratégies syndicales au Brésil: création et gestion de fonds de pension. In: DURAND, J.-P.; GASPARINI, W. (Orgs.). Le travail à l'épreuve des paradigmes. Tolouse: Octarès, 2007.

. Entre a solidariedade e o risco: sindicatos e fundos de pensão em tempos de governo Lula. 2007. Tese (Doutorado em Ciências Sociais) - Universidade Federal de São Carlos, 2007.

. "Domesticação" e/ou "moralização do capitalismo" no governo Lula: inclusão social via mercado e via fundos de pensão. Dados, Revista de Ciências Sociais, Rio de Janeiro, v. 52, n. 1, p. 157-182, 2009. Disponível em: <http://www.scielo.br/pdf/dados/ v52n1/v52n1a04.pdf $>$.

MELLO, Magno. A face oculta da reforma previdenciária. Brasília, DF: Letrativa, 2003. 
NEIBURG, Federico. A sociologia das relações de poder de Norbert Elias: Apresentação à edição brasileira. In: ELIAS, Norbert; SCOTSON, John L. (Orgs.). Os estabelecidos e os outsiders: sociologia das relações de poder a partir de uma pequena comunidade. Rio de Janeiro: Zahar, 2000.

PATURY, Felipe; OYAMA, Thaís. O curinga de Lula. Veja [revista], n. 1787, 29 jan. 2003. Disponível em: <http://veja.abril.com. br/290103/p_046.html>.

REIS, Adacir (Org.). Fundos de pensão em debate. Brasília, DF: Brasília Jurídica, 2002.

SASSERON, J. A presença dos participantes nas instâncias estatuárias. In: REIS, Adacir (Org.). Fundos de pensão em debate. Brasília, DF: Brasília Jurídica, 2002. p.171-178.

TOMIZAKI, Kimi. A herança operária entre a fábrica e a escola. Revista Tempo Social, v. 18, n. 1, p. 153-171, jun. 2006. Disponível em: $<$ http://www.scielo.br/pdf/ts/v18n1/30012.pdf $>$.

WAGNER, Anne-Catherine. Vers une Europe syndicale: une enquête sur la Confédération européenne des syndicats. Paris: Éditions du Croquant, Savoir/Agir, 2005. 